\title{
MJMR $\mid$ A STUDY TO IDENTIFY THE PERCEIVED STRESS AMONG FIRST YEAR BASIC B SC. NURSING STUDENTS IN A SELECTED COLLEGE OF NURSING IN KOLKATA (WEST BENGAL), INDIA
}

\author{
Ranu Bag \\ Govt. College of Nursing, N.R.S Medical College \& Hospital, Kolkata, West Bengal, India \\ *Correspondence Author's Email: ranu.bag@gmail.com
}

\begin{abstract}
Purpose: To explore the experience of the first year basic B Sc. nursing students, who are exposed to the clinical field of nursing and nursing profession for the first time and describe their sense of perceived stress. Objective: To assess the perceived stress among the first year basic B Sc. nursing students and to find out association between perceived stress and demographic variables. Method: A descriptive survey approach was taken at selected college of nursing. Total 67samples selected through non probability convenience sampling technique. A structured questionnaire used for demographic variables. The data was collected through the standardized tool of Cohen's perceived stress scale along with the rating scale of stress checklist. Result: Major findings of the study was found that out of 67 students, maximum of $43.828 \%$ have monthly family income of below Rupees 5000, 79.11\% of the students were away from home first time, $20.89 \%$ students had factors like could not pursue other courses and $88.05 \%$ has never been exposed to the hospital environment before. Based on the stress score, $73.14 \%$ students whose score was between 11 to 20 , were found to have mild stress. $23.8 \%$ whose score was between 21 to 30 had moderate stress and $2.98 \%$ students who scored between 0 to 10 were undergoing the least level of stress. It is recommended that further studies can be done with larger sample size and or among students of other professional courses. Conclusion/Outcome: The investigator observed that there was significant Association between perceived level of stress and the presence of precipitating factors i.e away from home first time, could not pursue other courses and monthly family income $\{$ chi square $(2)=5.99, P<0.05\}$. Other than this there was no significant Association between perceived stress with other selected variables.
\end{abstract}

\section{Keywords: Perceived Stress Level, 1st Year Basic B Sc. Nursing Students}

\section{INTRODUCTION}

\section{Background of the Study}

Stress is a term which has become a part and parcel of our present generation. Order to perform well certain degree of positive stress called Eustress is needed. Negative stress called distress occurs when a person fails unable to perform or to cope with a situation. Stress is a condition in the person experiences changes in the normal balance state. The World Health Organization has estimated that will be one of the leading cause of disability by the year 2020 .

Over the recent years there has been a growing concern about stress among nursing students. It has been estimated that $10 \%$ to $30 \%$ nursing students experience academic as well as clinical exposure related stress that affects their overall performance.
Various studies were conducted to identify stressful events of first year nursing students in the clinical setting and to determine how they cope with stressful events. The results showed that most of the students utilized seeking social support as categories of coping with problems of interpersonal relationship, initial experiences of feeling helpless.

Therefore nursing students need to assess their stress level and to find out the association between perceived stress and selected demographic variables of the first year basic B.Sc. nursing students during their early clinical practice.

The researcher also tried to help nursing educator to understand the difficulties of nursing students and assist them individually in order to promote the quality of clinical practice. 


\section{METHODOLOGY}

Study approach: Descriptive survey approach.

Setting of the study: N.R.S. Medical College \& Hospital

Study population: $1^{\text {st }}$ year Basic BSc. Nursing students.

\section{Sample size: 67}

Sampling technique: Non-probability convenience sampling technique.

Study tool and technique: Structured questionnaire used to collect socio-demographic data.

Cohen's perceived stress scale used to find out the stress level. Only interviewing techniques used to collect data.

Data analysis: The collected data was compiled, scrutinized, and analyzed by descriptive and inferential statistics.

Ethical consideration: Ethical permission was taken from Ethics \&Scientific Committee of N.R.S M C \& H. Informed consent was taken from the participants' prior data collection. Privacy and Confidentiality maintained throughout the study.

\section{RESULT}

Findings of Socio-demographic data shown in table 1.

Table 1: Frequency distribution of sociodemographic variables. $n=67$

\begin{tabular}{|c|c|c|}
\hline $\begin{array}{c}\text { Socio-demographic } \\
\text { variables }\end{array}$ & Frequency(f) & Percentage (\%) \\
\hline $\begin{array}{c}\text { 1.Monthly family income } \\
\text { Below Rs.5000 }\end{array}$ & 29 & 43.28 \\
Rs.5001-15000 & 28 & 41.79 \\
Above Rs.15000 & 10 & 14.93 \\
\hline 2.Presence of precipitating & & \\
factors & 53 & 79.11 \\
Away from home first time & 14 & 20.89 \\
Failed to pursue other course & & \\
\hline 3.Purpose of joining this & & 73.13 \\
course & 49 & 7.46 \\
Job security & 13 & \\
Interest in nursing & 5 & \\
Forced by family member & & \\
\hline
\end{tabular}

\begin{tabular}{|c|c|c|}
\hline $\begin{array}{c}\text { 4.Previously exposed to } \\
\text { hospital environment } \\
\text { Yes }\end{array}$ & 59 & \\
No & 8 & 12 \\
\hline 5.Residential status & & \\
Rural & 60 & 89.55 \\
Urban & 7 & 10.45 \\
\hline 6.Presence of nursing \\
personnel in family \\
Yes
\end{tabular}

Among 67 students $43.28 \%$ have monthly family income below Rs.5000 and $14.93 \%$ have monthly family income above Rs.15000. Majority (79.11\%) were away from home first time. 88\% students had exposed to hospital environment. Most of the students $(89.55 \%)$ were from rural community. $85 \%$ students had nursing personnel in their family.

Table 2 represents the stress scores measured by the standardized tool of Cohen's Perceived Stress Scale.

Table 2: Frequency distribution of students according to their level of perceived stress. $n=67$

\begin{tabular}{|l|c|c|}
\hline Stress level & Frequency(f) & Percentage (\%) \\
\hline Least & 2 & 2.98 \\
\hline Mild & 49 & 73.14 \\
\hline Moderate & 16 & 23.88 \\
\hline severe & nil & nil \\
\hline
\end{tabular}

Data presented that majority had mild level of perceived stress $(73.14 \%)$. Least stress level had among $2.98 \%$ students. There was no student under severe stress level.

Table 3 shows that there was statistically significant association between the perceived stress of the 1st year Basic BSc Nursing students and their selected demographic variables such as monthly family income, precipitating factors (i.e away from home first time, fail to pursue other courses) and purpose of joining this course at 0.05 level of significance. Other sociodemographic variables had no statically significant association with perceived stress among $1^{\text {st }}$ year Basic 
BSc. Nursing students.

Table 3: Association between the level of perceived stress and monthly family income \& presence of precipitating factors ( i.e away from home first time and failed to pursue other courses). $n=67$

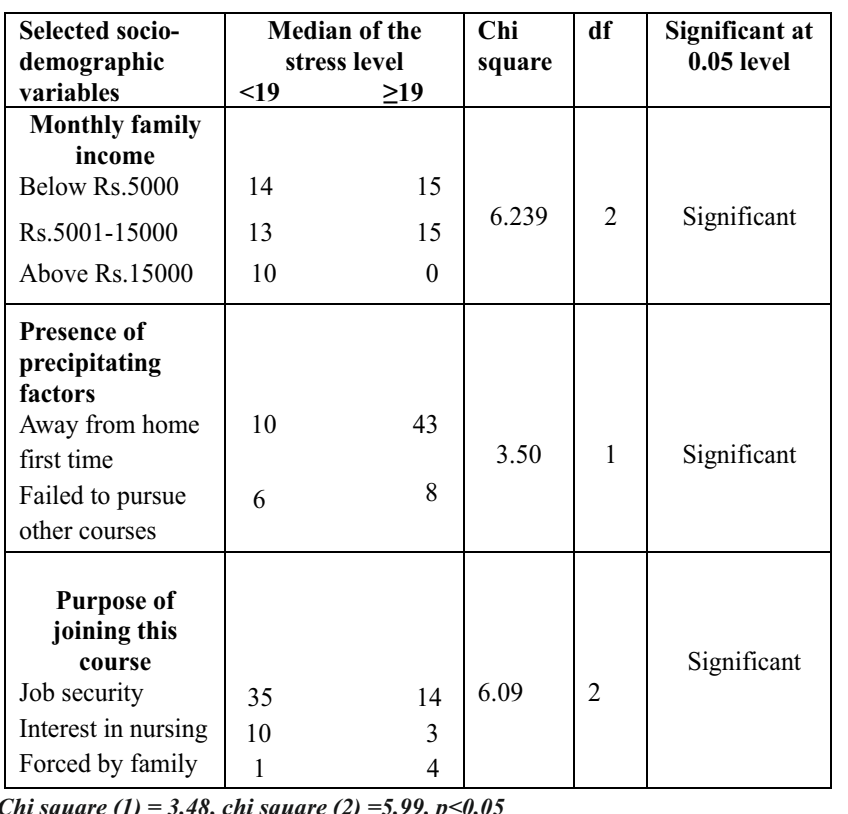

\section{DISCUSSION}

Discussion related to identify the person stress level among first year basic B.Sc. nursing students: A descriptive study was conducted by (Prasad, et al., 2013) among 60 first year B.Sc. nursing students to determine the level of stress. The result showed that only one student $1.77 \%$ had severe stress 46.7 percent had moderate stress and remaining 51.6\% had mild stress.

A study was conducted by (Singh, et al., 2011) to find out the level of stress associated with demographic variables on 1st year GNM students of National Institute of Nursing Education, PGIMER, Chandigarh in which among 44 students $63.6 \%$ had moderate stress, $34.10 \%$ had mild stress and $2.3 \%$ had severe stress.

Discussion related to find out the association between perceived stress and selected demographic variables:

(Shukla, et al., 2013) conducted a cross sectional study on $591^{\text {st }}$ year GNM students to assess the level of stress related to demographic variables. The result showed that the mean score was 59.3 in directing significant stress.

(Liu, et al., 2015) conducted a descriptive study in Macao nursing college to determine the stress among nursing students in clinical learning environment. The result indicated that no statistical significance was found between stress and selected demographic variables.

\section{CONCLUSION}

The study findings showed that a majority number of students have mild stress where as a significant percentage found to have moderate stress. It was found that there was no significant. Association between level of stress and demographic variables except that with precipitating factors such as away from home 1st time, failed to pursue other courses and monthly family income were found to be that is statistically significant at 0.05 level of significance.

\section{Implications}

Nursing Practice- Identification of perceived stress by the trained nurses can help in learning effective intervention and strategies like counseling, open communication, meditation and yoga in order to prevent stress.

Nursing Education- Study results could have greater effect on nursing education as well as nursing superintendent, sister tutor, sister in charge and staff nurses from different nursing departments can utilize these findings to direct their students during their clinical practices positively.

Nursing administration- By using the data obtained from these study administrators should establish a student support system through which the student can be equipped with effective coping strategies.

Nursing research- It is important that nursing researchers conduct methodological studies with the purpose of establishing and refining a standardized instrument for identifying perceived stress among nursing students during their clinical practice. Additional research is needed to explore the perception of the nursing tutors regarding the perceived stress faced by the young and nervous nursing students 
during their early exposure in clinical practice.

\section{RECOMMENDATIONS}

1. A similar study can be replicated on a large sample for making generalization.

2. A comparative study can be conducted between Government and private BSc nursing students.

3. A similar study can be done to assess the knowledge of stress among students after providing information booklet regarding perceived stress and its management.

\section{Conflict of Interest}

The authors declare that they have no conflict of interest.

\section{ACKNOWLEDGEMENT}

A heartfelt gratitude to the Principal of N.R.S Medical College, Kolkata and Principal of Medical College, Kolkata.A sincere gratitude to M.S.V.P of N.R.S Medical College \& Hospital and M.S.V.P of Medical College, Kolkata.I extremely grateful to all my colleagues. Words of acknowledgement would be incomplete if I do not express the sincere thanks to all participants. I am grateful to my all well wishers though not specially mentioned thanking you and all.

\section{REFERENCE}

Beck, D.L. \& Srivastava, R. (1991) Perceived level of stress in $1^{\text {st }}$ Year GNM nursing students. Journal of nursing Education

Burns Nancy, K. \& Susan, G. (2008) Understand Nursing Research: $4^{\text {th }}$ edition, Elesevier Publication, Noida

Cohen, S., Kamarck, T., \& Mermelstein, R. (1983) Perceived Stress Scale, A Global measures of perceived stress. Journal of Health and Social Behavior, 24, pp: 385-396.

Deary, I.J., Watson, R., Hogston, R. (2003) A longitudinal cohort study of stress perceived among GNM students. Iranian journal of nursing and midwifery research 18(4) pp:340-342

Dhar R, Walia I, Das K. (2009) A descriptive study to assess the causes of stress and coping strategies used by the newly admitted basic B.Sc. Nursing students. Nursing and Midwifery Research Journal, 5(1), pp:31-37.

KEVIN. (Nov. 2015) Assess the level of stress perceived of student nurse during their initial clinical practice with a view to develop selfinstruction Module, Journal of Research. Pg.-11.

Kathar, A. \& Wejdam, R.N., (2014) Sources of Perceived stress and coping behaviors in clinical practice among GNM $1^{\text {st }}$ year Nursing students. International Journal of Humanities and Social Science 4(6) pp:20

Lazarus, R.S. (1990) Theory based stress measurement. Psychological Inquery, 1(1) pp:3-13

Lamk A.L. (2010) Stress in the medical profession on and sits roots in medical school

Liu, M., Gu, K., Wong, T.K.S. \& Watson, R. (2015) Percieved stress among Macao nursing students in the clinical learning environment. International Journal of Nursing Sciences, 55(2)

Polit Denis F, Beck \& Chernl, T. (2010) Nursing research: $8^{\text {th }}$ edition, Wolter Kluwer Publication, New Delhi, India

Prasad CV, Suresh A, Thomas DK, Pritty MK, Beebi S, Multazim V, (2013 Jan); The level of stress adopted by $1^{\text {st }}$ year GNM nursing students Archives of medicine and Health Sciences 1, P.-19.

Sharma SK. (2015) Nursing Research \& Statistics New, $2^{\text {nd }}$ edition Elesevier Publication, India

Sharma, N. \& Kaur, A. (2011) Factors associated with stress among $1^{\text {st }}$ year GNM nursing students. Research Journal.

Sheu, S., Lin, H.S. \& Hwang, S.I., (2002) Perceived Stress of GNM nursing students during their initial period of clinical practice: the effect of coping behaviors, International Journal of Nursing Studies 39(2) pp:165-75

Singh, C., Sharma, S. \& Sharma, R.K., (2011) Level of stress and coping strategies used by nursing interns, Nursing \& Midwifery Research Journal, 7 pp:152-60

Sukla, A., Kalra, G. \& Pakhare, (2013) Understanding stress and coping mechanism in student Nurses available from Sri Lanka. Journal of Psychiatric, 4(2), pp: 29 